\title{
Different fungal peroxidases oxidize nitrophenols at a surface catalytic tryptophan
}

\author{
Dolores Linde, Iván Ayuso-Fernández, Francisco J. Ruiz-Dueñas, Angel T. Martínez* \\ Centro de Investigaciones Biológicas, CSIC, Ramiro de Maeztu 9, E-28040 Madrid, Spain \\ *E-mail: ATMartinez@,cib.csic.es
}

\begin{abstract}
Dye-decolorizing peroxidase (DyP) from Auricularia auricula-judae and versatile peroxidase (VP) from Pleurotus eryngii oxidize the three mononitrophenol isomers. Both enzymes have been overexpressed in Escherichia coli and in vitro activated. Despite their very different threedimensional structures, the nitrophenol oxidation site is located at a solvent-exposed aromatic residue in both DyP (Trp377) and VP (Trp164), as revealed by liquid chromatography coupled to mass spectrometry and kinetic analyses of nitrophenol oxidation by the native enzymes and their tryptophan-less variants (the latter showing 10-60 fold lower catalytic efficiencies).
\end{abstract}

Keywords: Nitrophenols; heme peroxidases; long-range electron transfer (LRET); catalytic tryptophan; dye-decolorizing peroxidase (DyP); versatile peroxidase (VP)

Abbreviations used: CI, compound I; CII, compound II; DyP, dye-decolorizing peroxidase; $\mathrm{E}^{\circ}$, standard reduction potential; $k_{\text {cat }}$, turnover number; $k_{\text {cat }} / K_{\mathrm{m}}$, catalytic efficiency; $K_{\mathrm{m}}$, Michaelis constant; LC-PDA/MS, liquid chromatography coupled to photodiode-array and massspectrometry detection; LiP, lignin peroxidase; LRET, long-range electron transfer; MnP, manganese peroxidase; PDB, protein data bank; RS, resting state; VP, versatile peroxidase

\section{Introduction}

Nitrated phenol derivatives (nitrophenols) are versatile building blocks for the industrial synthesis of dyes, plastics and fungicides, among other chemicals. Nitrophenol exists as three (ortho, meta and para) isomers with different acidities and water solubilities. Although there are no known natural sources of nitrophenols, these compounds are found in air, water and soil as a consequence of the industrial activity [1]. Additional nitration of mononitrophenols gives six dinitrophenol isomers (2,3-, 2,4-, 2,5-, 2,6-, 3,4- and 3,5-dinitrophenol). Among them, 2,4dinitrophenol has the highest industrial interest, being used for the production of picric acid, sulfur black dye, and 2,4-diaminophenol (amidol developer in photography).

In former studies, no oxidation of para-nitrophenol was detected by lignin peroxidase (LiP), manganese peroxidase (MnP), and laccase from Phanerochaete chrysosporium and Trametes versicolor, although this compound was converted to 4-nitroanisole and 1,2-dimethoxy-4nitrobenzene by the former fungus through a combination of hydroxylation and methylation 
reactions [2]. More recently para-nitrophenol oxidation by several dye-decolorizing peroxidases (DyPs) was compared with oxidation by $P$. chrysosporium LiP, Coprinopsis cinerea peroxidase, and soybean peroxidase [3]. Differences in turnover numbers were observed between the analyzed DyPs, the highest values being comparable to those of LiP and C. cinerea peroxidase, with soybean peroxidase as the only enzyme unable to oxidize this substrate. In Auricularia auricula-judae DyP studies, an overall scheme for nitrophenol oxidation was proposed, initiated by the formation of its phenoxy radical, which adopts different mesomeric forms. This radical would undergo spontaneous reactions, including the release of the nitro group yielding parabenzoquinone, and its reaction with a second nitrophenol molecule forming dinitrophenol. Due to the short life-span of the nitrating radicals, it was suggested that the latter reaction will take place in a confined space within or near the heme channel [4,5].

Related with this, when the crystallographic structure of Bjerkandera adusta DyP was solved in complex with 2,6-dimethoxyphenol (PDB 3VXJ), a binding site at the entrance of the heme cavity was described with a network of water molecules, two amino-acid residues and the heme 6-propionate involved in electron and proton transfer from substrate to DyP [6]. In contrast, oxidation of phenols by the A. auricula-judae DyP was proposed to take place at a solventexposed tyrosine (Tyr337), via a long-range electron transfer (LRET) pathway, although a solvent-exposed tryptophan was also found in the first crystal structure of this enzyme $[4,7]$. Finally, the major catalytic role of the latter residue of A. auricula-judae DyP (Fig. 1A) in LRET oxidation of 2,6-dimethoxyphenol and other model substrates (as a high turnover oxidation site) was demonstrated by activity loss of the W377S variant, although the main heme access channel would also act as a low turnover substrate oxidation site, as shown by the loss of this activity when the heme channel was occluded by directed mutagenesis [8].
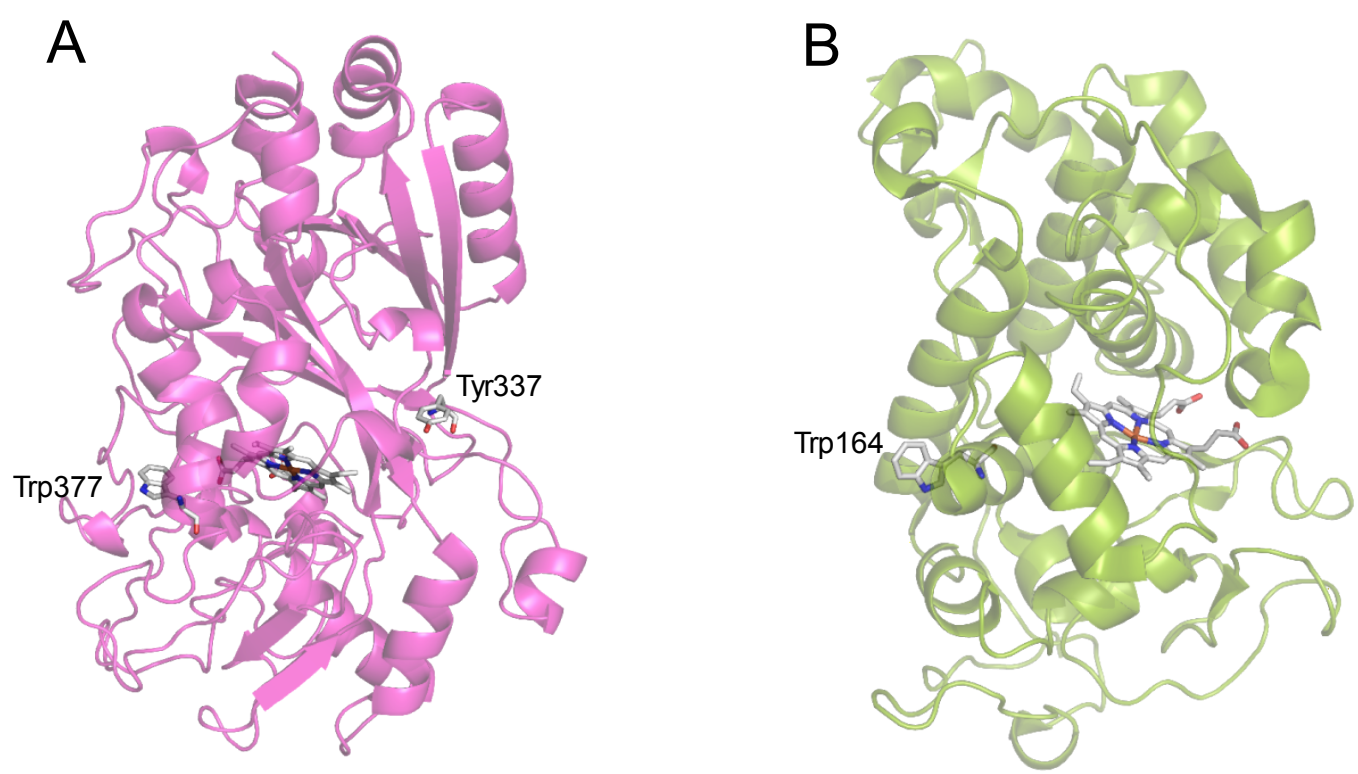

Fig 1. Ribbon type representations of the crystal structures of the Escherichia coli-expressed DyP of $A$. auricula-judae (A) and VP of $P$. eryngii (B) compared in the present study, showing (as CPK-colored sticks) the solvent-exposed tryptophan of both enzymes (Trp377 and Trp164, respectively) and solventexposed tyrosine (Tyr337) of DyP, together with the heme cofactors. From PDB entries 4W7J and 2BOQ, respectively $[8,9]$. 
In a similar way, versatile peroxidase (VP), the third family of ligninolytic peroxidases together with $\mathrm{LiP}$ and $\mathrm{MnP}$, is able to oxidize phenols (and low redox-potential dyes) at two catalytic sites: i) a high catalytic-efficiency site (Trp164 in Pleurotus eryngii VPL2, Fig. 1B) where high redox-potential substrates (like veratryl alcohol and lignin) are also oxidized; and ii) a low catalytic-efficiency site located at the main heme access channel, as shown by the activity detected in the W164S variant $[10,11]$.

In the present paper, oxidation of nitrophenols by DyP (from A. auricula-judae), VP (from $P$. eryngii), one DyP mutated variant at the heme access channel and other at the surface exposed tyrosine, and two variants at the catalytic tryptophan of both enzymes was investigated, with high activity loss for the two tryptophan-less variants. Simultaneously, we showed that the chromatographied oxidation products from the three nitrophenol isomers were the same for both enzymes.

\section{Material and methods}

\subsection{Chemicals}

Ortho-nitrophenol (2-nitrophenol), meta-nitrophenol (3-nitrophenol), para-nitrophenol (4nitrophenol), 2,4-dinitrophenol and sodium nitrite were obtained from Merck.

\subsection{Enzyme production, activation and purification}

Non-mutated recombinant (hereinafter native) A. auricula-judae DyP and its G169L, W377S and Y337S variants were expressed as inclusion bodies in E. coli BL21(DE3)pLysS cells with the pET23a-DyP vector containing the mature protein sequences, in vitro activated, and purified as described elsewhere [12]. Native $P$. eryngii VP and its W164S variant were expressed as inclusion bodies in $E$. coli $\mathrm{W} 310$ cells with the pFLAG-VP vector containing the mature protein sequences, in vitro activated, and purified as described elsewhere [13]. The correct folding and heme cofactor incorporation to native enzymes and variants was confirmed by electronic absorption spectra with the characteristic Soret band at 405 (DyP) and 410 (VP) nm, and the two small bands around 500 and $650 \mathrm{~nm}$ (Fig. S1).

\subsection{Chromatographic analysis of nitrophenol reactions}

Reactions were performed at $25^{\circ} \mathrm{C}$ in $3-\mathrm{ml}$ final volume, mixing native or mutated DyP and VP $(0.44 \mu \mathrm{M})$ with $1 \mathrm{mM}$ substrate (ortho, meta or para nitrophenol) and $0.1 \mathrm{M}$ acetate, $\mathrm{pH}$ 4.3. Reactions were started by adding $\mathrm{H}_{2} \mathrm{O}_{2}$ at final concentration of $1 \mathrm{mM}$. At $0,10,30,60$ and 120 min of reaction, $0.5 \mathrm{ml}$ aliquots were collected and the reactions were stopped by adding $10 \mu 1$ of $4.4 \mathrm{mM}$ sodium azide.

The substrate consumption and chromatographied reaction products (in $25 \mu 1$ samples) were analyzed using an Agilent HPLC equipment fitted with a ACE3 C18 column $(150 \times 2.1 \mathrm{~mm}$, and $3 \mu \mathrm{M}$ particle size) and isocratic acetonitrile $(15 \% \mathrm{v} / \mathrm{v}$ for meta-nitrophenol reactions and $20 \%$ $\mathrm{v} / \mathrm{v}$ for the rest) in ammonium formate $(0.1 \% \mathrm{v} / \mathrm{v})$ as mobile phase, at a flow rate of $0.2 \mathrm{ml} \mathrm{min}^{-1}$, at $25^{\circ} \mathrm{C}$. Elution was monitored by absorbance in the range of 200 to $500 \mathrm{~nm}$ (PDA), and mass detection in the range of 100 to $200 \mathrm{Da}$. 
The retention times of ortho-nitrophenol (22.8 $\mathrm{min})$, meta-nitrophenol (24.4 min), paranitrophenol (14.9 $\mathrm{min}$ ) and 2,4-dinitrophenol (16.5 $\mathrm{min}$ ) were obtained from authentic standards, while the retention time of 2,6-dinitrophenol (12.0 $\mathrm{min})$ was taken from the literature [4]. Molecular ions at $\mathrm{m} / \mathrm{z} 137[\mathrm{M}-\mathrm{H}]^{-}$and $183[\mathrm{M}-\mathrm{H}]^{-}$were found for the mono- and di-nitrated phenols, respectively. Calibration curves were obtained for quantification of products and remaining substrates in the different reactions (Fig. S2).

\subsection{Kinetics of nitrophenol oxidation}

Steady-state kinetic constants were determined in triplicate reactions by spectrophotometric measurement of the initial oxidation rates of nitrophenol isomers $(0.2-15 \mathrm{mM}$ concentration), followed at $405 \mathrm{~nm}$, in $0.1 \mathrm{M}$ acetate, $\mathrm{pH} 4.3$, using $1 \mathrm{mM} \mathrm{H}_{2} \mathrm{O}_{2}$ and $0.44 \mu \mathrm{M}$ enzyme, at $25^{\circ} \mathrm{C}$. Previously, molar extinction coefficients for the oxidation of ortho- $\left(\varepsilon_{405} 2660 \mathrm{M}^{-1} \mathrm{~cm}^{-1}\right)$, meta$\left(\varepsilon_{405} 3060 \mathrm{M}^{-1} \mathrm{~cm}^{-1}\right)$ and para-nitrophenol $\left(\varepsilon_{405} 2230 \mathrm{M}^{-1} \mathrm{~cm}^{-1}\right)$ were calculated from $0.1 \mathrm{mM}$ substrate reactions with $3.5 \mu \mathrm{M}$ DyP, under the conditions described above (Fig. S3). After spectra stabilization the amount of remaining substrate was quantified by liquid chromatography (LC) coupled to photodiode array (PDA) and mass spectrometry (MS) detectors, and the molar extinction coefficients were calculated from the variation of absorbance using the Lambert Beer equation [1]:

$$
[1] \mathrm{Abs}=\varepsilon \mathrm{L} \mathrm{c}
$$

where Abs is the absorbance, $\varepsilon$ is the molar extinction coefficient, $\mathrm{L}$ is the light path length, and $\mathrm{c}$ is the molar concentration.

Plotting and analysis of kinetic curves were carried out with SigmaPlot (version 11.0). Apparent affinity constant $\left(K_{\mathrm{m}}\right)$, turnover number $\left(k_{\mathrm{cat}}\right)$ and their standard errors were estimated by non-linear least-squares fitting to the Michaelis-Menten model. Catalytic efficiency and its standard error was estimated by fitting to the Michaelis-Menten normalized equation [2]

$$
[2] \mathrm{v}=\left(k_{\mathrm{cat}} / K_{\mathrm{m}}\right)[\mathrm{S}] /\left(1+[\mathrm{S}] / K_{\mathrm{m}}\right)
$$

Finally, para-nitrophenol $(25 \mathrm{mM})$ oxidation by $A$. auricula-judae DyP and P. eryngii VP $(0.44 \mu \mathrm{M})$ was measured in the presence of $0-100 \mu \mathrm{M} \mathrm{NaNO} \mathrm{Na}_{2}$ to investigate a possible stimulatory or inhibitory effect.

\subsection{Comparison of DyP and VP standard reduction potentials}

The reduction potentials $\left(\mathrm{E}^{\circ \prime}\right)$ of the compound I/resting state $(\mathrm{CI} / \mathrm{RS})$ pairs of $A$. auricula-judae DyP and $P$. eryngii VP were calculated from equilibrium concentrations estimated by stoppedflow rapid spectrophotometry [14]. RS conversion into CI was followed in a stopped-flow equipment (Bio-Logic) synchronized with a diode-array detector (J\&M), and the BioKine software. The experiments were made in $100 \mathrm{mM}$ tartrate, $\mathrm{pH} 3$, at $25^{\circ} \mathrm{C}$, by mixing enzyme $(8$ $\mu \mathrm{M}$ DyP and $4 \mu \mathrm{M}$ VP) with different concentrations of $\mathrm{H}_{2} \mathrm{O}_{2}$ (1-12 molar equivalents till equilibrium) for 3 seconds. The $\mathrm{E}^{\mathrm{o}}(\mathrm{CI} / \mathrm{RS})$ was determined using the Nernst equation at equilibrium [3]: 


$$
\text { [3] } \Delta \mathrm{E}^{\mathrm{ol}}=(\mathrm{RT} / \mathrm{nF}) \ln \mathrm{K}^{\prime}
$$

that correlates the difference of reduction potentials between enzyme and substrate with the equilibrium constant $\mathrm{K}^{\prime}$. $\mathrm{R}$ is equal to $8.31 \mathrm{~J} \mathrm{~K}^{-1} \mathrm{~mol}^{-1}$, $\mathrm{T}$ is set to $298 \mathrm{~K}$, $\mathrm{n}$ represents the number of electrons transferred in a single reaction step of the redox couple, and $\mathrm{F}$ (the Faraday constant) is $96,485 \mathrm{~J} \mathrm{~V}^{-1} \mathrm{~mol}^{-1}$. $\mathrm{K}^{\prime}$ represents the $\mathrm{CI} / \mathrm{RS}$ pair equilibrium constant, which is calculated as follows [4]:

$$
[4] \mathrm{K}^{\prime}=\left(\left[\mathrm{H}_{2} \mathrm{O}_{2}\right][\mathrm{RS}]\right) /[\mathrm{CI}]
$$

The amounts of $\mathrm{CI}$ and RS were quantified using their extinction coefficients at the equilibrium (i.e. when the spectral changes ended, during $\mathrm{H}_{2} \mathrm{O}_{2}$ addition; see Fig. S4) and the reduction potential of the pair $\mathrm{H}_{2} \mathrm{O}_{2} / \mathrm{H}_{2} \mathrm{O}$ at $\mathrm{pH} 3\left(\mathrm{E}^{\mathrm{ol}}=1.56 \mathrm{~V}\right)$ [15]. The RS extinction coefficients values were $\varepsilon_{405 \mathrm{~mm}}=117000 \mathrm{M}^{-1} \mathrm{~cm}^{-1}$ for DyP and $\varepsilon_{410 \mathrm{~mm}}=150000 \mathrm{M}^{-1} \mathrm{~cm}^{-1}$ for VP. CI extinction coefficients values were calculated after converting all the RS enzyme into CI using $10 \mathrm{H}_{2} \mathrm{O}_{2}$ equivalents, ensuring there is no auto-reduction to CII. The values obtained were $\varepsilon_{405 \mathrm{~nm}}=65750 \mathrm{M}^{-1} \mathrm{~cm}^{-1}$ for DyP, and $\varepsilon_{410 \mathrm{~nm}}=53300 \mathrm{M}^{-1} \mathrm{~cm}^{-1}$ for VP.

At a specific wavelength (405 nm for DyP and $410 \mathrm{~nm}$ for VP), the absorbance is an additive measurement of those of the individual components of a mixture. Therefore, using the $410 \mathrm{~nm}$ (Soret band) extinction coefficients for RS and CI the quantification of the CI/RS redox pair at equilibrium is possible using the following equation [5]:

$$
[5] \mathrm{A}_{410}=\varepsilon_{410-\mathrm{RS}}[\mathrm{RS}] 1+\varepsilon_{410-\mathrm{CI}}[\mathrm{CI}] 1
$$

where 1 is the path length of the stopped-flow cuvette.

\subsection{Molecular docking}

AutoDock 4.2 [16] was used for docking ortho-, meta- and para-nitrophenol on the crystal structures of the recombinant DyP and VP used in the present study (PDB entries 4W7J and 2BOQ, respectively). During simulation, the structure of the protein was kept rigid while that of the ligands was allowed to be flexible, and multiple Lamarckian Genetic Algorithm runs occurred, each one providing one predicted binding mode, followed by cluster analysis at the end of the simulation. Grids of probe atom interaction energies and electrostatic potential were generated by the AutoGrid program present in AutoDock 4.2 (a grid spacing of $0.375 \AA$ was used). For each calculation, one job of 100 docking runs was performed using a population of 150 individuals and an evaluation number of $2.5 \times 10^{7}$.

\section{Results and discussion}

\subsection{Chromatographic analyses with native and tryptophan-less enzymes}

For chromatographic and spectrophotometric (kinetic) analyses, oxidation of the three nitrophenol isomers by the recombinant $\mathrm{DyP}$ and $\mathrm{VP}$ was performed at optimal $\mathrm{pH} 4.3$ [4]. The results from chromatographic analyses of the reaction mixtures (using LC-PDA/MS) reveal that DyP and VP oxidize the three mononitrophenol isomers (ortho, meta and para), with significant 
decreases of substrate concentration by both enzymes. However, only minor peaks of reaction products (dinitrophenols) were detected, revealing that mononitrophenol oxidation mainly results in non-chromatographied products.

In this way, the chromatographic analyses of ortho-nitrophenol oxidation show that $52 \%$ of substrate was converted by DyP and $37 \%$ by VP, within $30 \mathrm{~min}$, although only $1.5 \%$ and $1.2 \%$ of 2,4-dinitrophenol were obtained, respectively (Fig. 2A). 2,4-Dinitrophenol was the main product observed, but 2,6-dinitrophenol and two minor peaks with retention time of 4.9 and 9.6 min and molecular ion of $\mathrm{m} / \mathrm{z} 183[\mathrm{M}-\mathrm{H}]^{-}$(corresponding to the mass of dinitrophenols) were also detected (Fig. S5). Although no oxidation products were detected from meta-nitrophenol (neither by PDA nor MS detection) similar transformation rates after 30 min reaction $(52 \%$ and $20 \%$ by DyP and VP, respectively) were estimated from peak decrease in the LC-PDA/MS analyses (Fig. 2B and Fig. S6). Finally, after 30 min of reaction with para-nitrophenol, 26\% and 35\% substrate was transformed by DyP and VP, with 2,4-dinitrophenol as the only chromatographied product (corresponding to $2.5 \%$ and $3.7 \%$ of substrate, respectively) (Fig. 2C and Fig. S7).
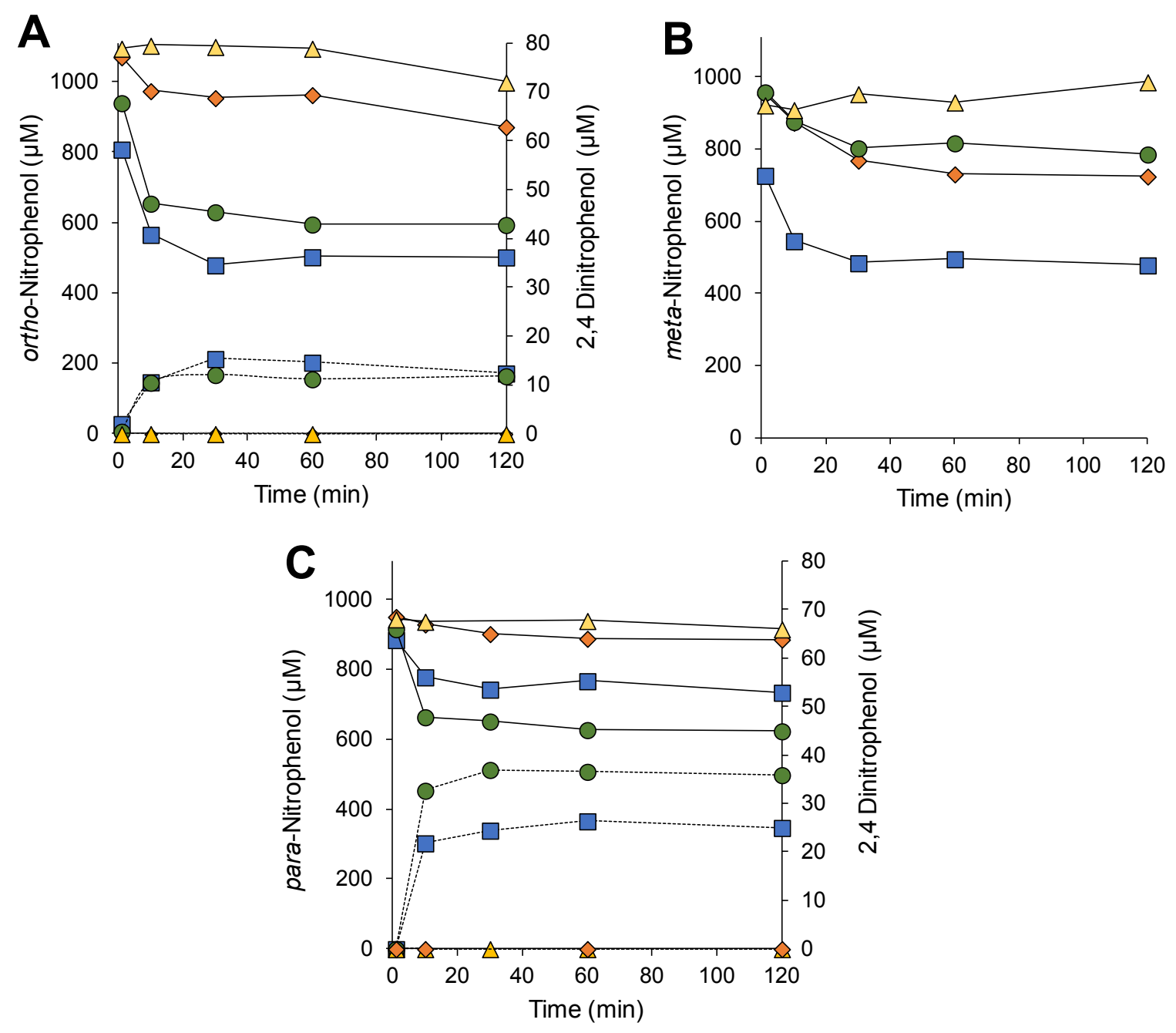

Fig. 2. Time course of ortho- (A), meta- (B) and para-nitrophenol (C) oxidation by native A. auriculajudae DyP (squares) and P. eryngii VP (circles), and DyP W377S (diamonds) and VP W164S (triangles) variants. Decrease of the nitrophenol substrate is shown by continuous lines, while the 2,4-dinitrophenol produced from the ortho and para substrates is shown by dashed lines. 
As already mentioned, the previously solved crystal structures of the E. coli-expressed native DyP (PDB 4W7J) and VP (PDB 2BOQ) include two solvent-exposed tryptophan residues involved in substrate oxidation $[9,17]$ (Fig. 1), which were here substituted with serine residues by site-directed mutagenesis. As for native enzymes, the eventual products and remaining ortho, meta and para substrates were quantified after different reaction times with the two tryptophanless variants (Fig. 2 and Figs. S5-S7). The results obtained reveal that substitution of the Trp377 in DyP (diamonds in Fig. 2) or the Trp164 in VP (triangles in Fig. 2) strongly reduced oxidation of nitrophenols in 2-h incubation experiments, preventing 2,4-dinitrophenol formation.

\subsection{Steady-state kinetics with native and mutated enzymes}

Steady-state kinetic analyses provide additional information to that obtained from the chromatographic analyses of 2-h reactions. The latter revealed that the 2,4-isomer, and other minor dinitrophenol products, only represent $2-9 \%$ of the substrate conversion (estimated from peak decrease) due to formation of non-chromatographied condensation products in agreement with previous studies [4]. Therefore, extinction coefficients of the whole reaction products were obtained, and used in kinetic analyses (Fig. 3).
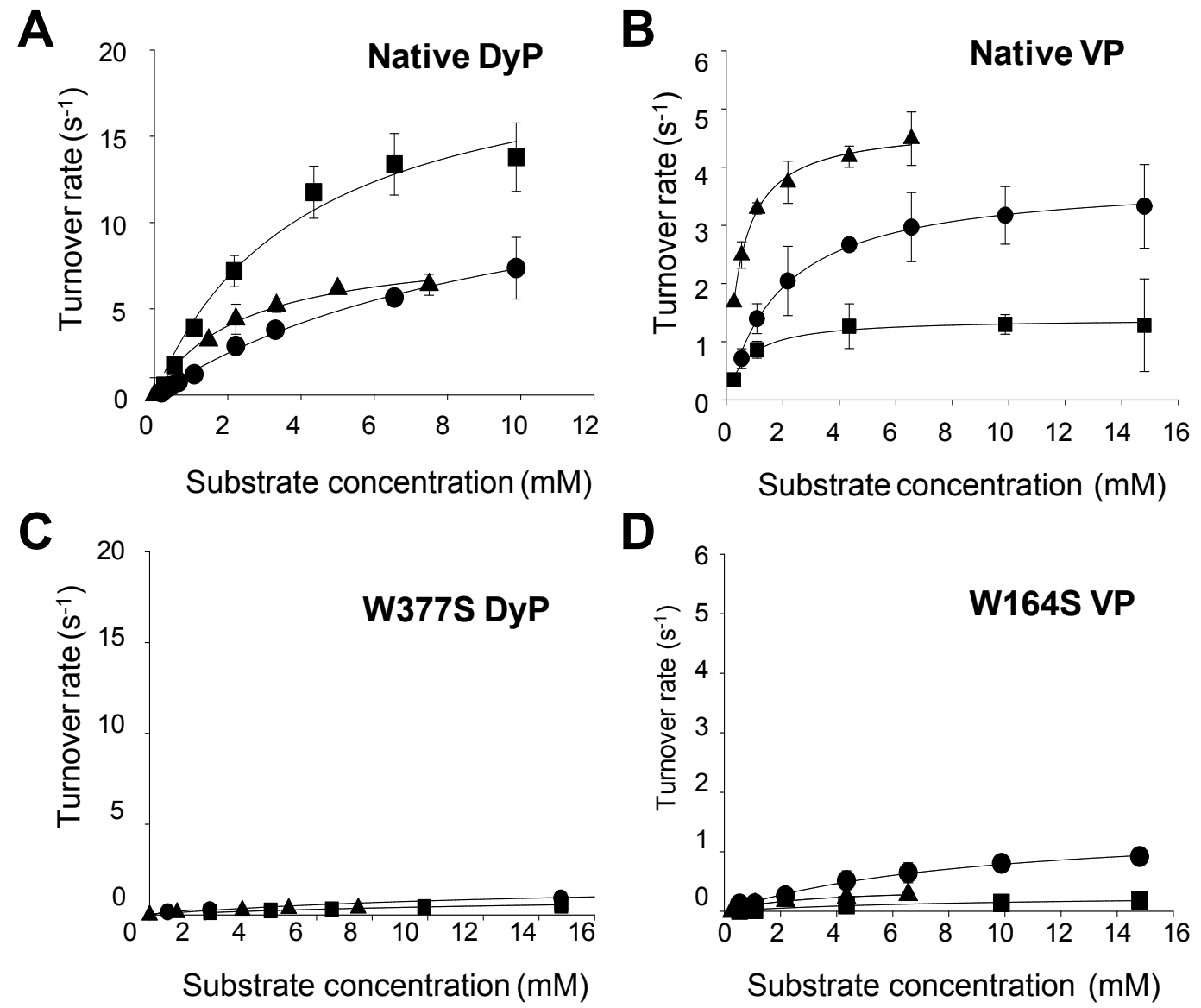

Fig. 3. Kinetics of nitrophenol oxidation (ortho, meta and para isomers in triangles, squares and circles, respectively) by native $A$. auricula judae DyP (A), its W377S variant (C), native $P$. eryngii $\mathrm{VP}(\mathbf{B})$ and its W164S variant (D). Means and standard errors are shown. 
The constants obtained (Table 1) show slightly higher $k_{\text {cat }}$ values for DyP than for VP, whereas VP exhibits higher affinity (lower $k_{\mathrm{m}}$ values) than DyP for the three nitrophenol isomers. The two peroxidases also showed differences in the preferred isomer used as substrate: meta for DyP $\left(16.9 \mathrm{~s}^{-1}\right)$ (in contrast, the meta isomer is the worst substrate of VP with a maximal turnover of only $\left.1.4 \mathrm{~s}^{-1}\right)$ and ortho for VP $\left(4.7 \mathrm{~s}^{-1}\right)$. The differences in kinetic constants and substrate preferences could be related with the presence of different amino-acid residues surrounding the catalytic tryptophan in both enzymes (Fig 4). This hypothesis is supported by previous studies that have demonstrated that the VP catalytic tryptophan environment contributes to the oxidation rate of high-redox-potential substrates and enzyme-product complex dissociation [18]. To further analyze substrate interactions at the catalytic tryptophan environment, docking simulations were performed as described in the next section.

Table 1. Steady-state kinetic constants $-K_{\mathrm{m}}(\mathrm{mM}), k_{\mathrm{cat}}\left(\mathrm{s}^{-1}\right)$ and $k_{c a l} / K_{\mathrm{m}}\left(\mathrm{s}^{-1} \cdot \mathrm{mM}^{-1}\right)$ - of native DyP and its G169L, W377S and Y337S variants, and native VP and its W164S variant on the three nitrophenol isomers. Reactions were performed at $25^{\circ} \mathrm{C}$ in $0.1 \mathrm{M}$ acetate, $\mathrm{pH} 4,3$, using $1 \mathrm{mM} \mathrm{H}_{2} \mathrm{O}_{2}$ and $0.44 \mu \mathrm{M}$ enzyme. Means and standard errors are shown.

\begin{tabular}{lccccccccc}
\hline & \multicolumn{3}{c}{ ortho-Nitrophenol } & \multicolumn{3}{c}{ meta-Nitrophenol } & \multicolumn{3}{c}{ para-Nitrophenol } \\
\cline { 2 - 10 } & $K_{\mathrm{m}}$ & $k_{\text {cat }}$ & $k_{\text {cat }} / K_{\mathrm{m}}$ & $K_{\mathrm{m}}$ & $k_{\text {cat }}$ & $k_{\text {cat }} / K_{\mathrm{m}}$ & $K_{\mathrm{m}}$ & $k_{\text {cat }}$ & $k_{\text {cat }} / K_{\mathrm{m}}$ \\
\hline DyP & $2.4 \pm 0.4$ & $8.7 \pm 0.5$ & $3.7 \pm 0.4$ & $2.8 \pm 0.9$ & $16.9 \pm 1.9$ & $6.1 \pm 1.4$ & $8.9 \pm 0.9$ & $13.5 \pm 0.7$ & $1.5 \pm 0.1$ \\
W377S & $3.3 \pm 0.9$ & $0.6 \pm 0.1$ & $0.2 \pm 0.0$ & $12.1 \pm 2.0$ & $0.9 \pm 0.1$ & $0.1 \pm 0.0$ & $18.6 \pm 5.5$ & $2.2 \pm 0.3$ & $0.1 \pm 0.0$ \\
Y337S & $3.5 \pm 0.8$ & $15.9 \pm 1.5$ & $4.6 \pm 0.7$ & $2.8 \pm 0.5$ & $15.8 \pm 0.9$ & $5.6 \pm 0.7$ & $15.9 \pm 5.3$ & $16.2 \pm 2.9$ & $1.0 \pm 0.2$ \\
G169L & $5.9 \pm 2.1$ & $13.1 \pm 2.6$ & $2.2 \pm 0.3$ & $3.2 \pm 0.6$ & $13.5 \pm 0.9$ & $4.2 \pm 0.6$ & $9.9 \pm 1.6$ & $13.7 \pm 1.1$ & $1.4 \pm 0.1$ \\
\hline VP & $0.5 \pm 0.1$ & $4.7 \pm 0.1$ & $9.2 \pm 0.5$ & $0.7 \pm 0.1$ & $1.4 \pm 0.0$ & $1.9 \pm 0.3$ & $1.9 \pm 0.1$ & $3.8 \pm 0.1$ & $1.9 \pm 0.1$ \\
W164S & $2.0 \pm 0.5$ & $0.7 \pm 0.1$ & $0.3 \pm 0.0$ & $9.6 \pm 3.1$ & $0.3 \pm 0.0$ & $0.1 \pm 0.0$ & $9.0 \pm 1.5$ & $1.5 \pm 0.1$ & $0.2 \pm 0.0$ \\
\hline
\end{tabular}
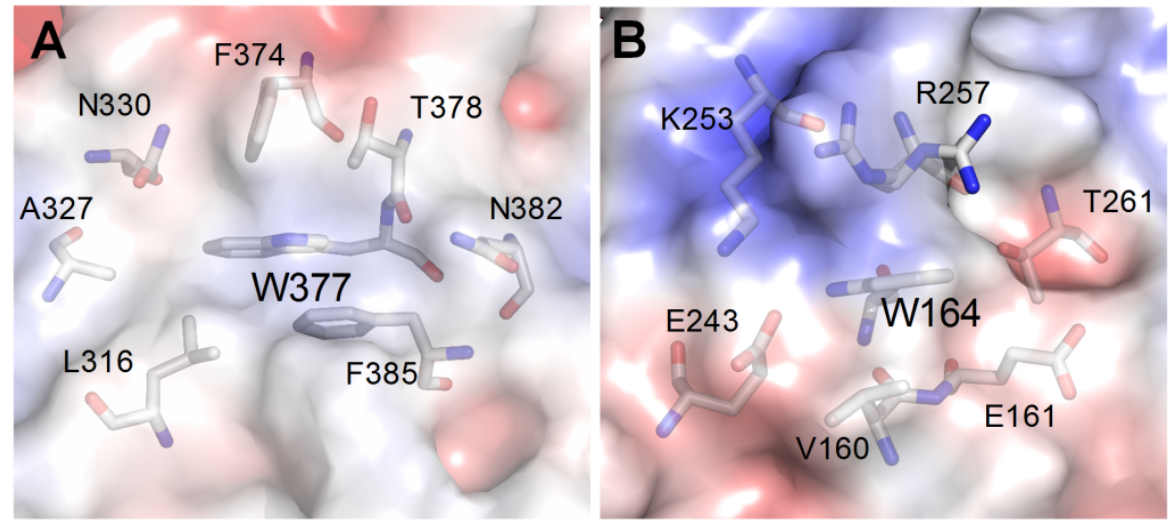

Fig 4. Catalytic tryptophan environment in the crystal structures of $A$. auricula-judae DyP (A) and $P$. eryngii VP (B) expressed in E. coli. DyP Trp377 and VP Trp164, and surrounding exposed residues are shown as CPK-colored sticks. The semitransparent solvent-access surfaces are colored by electrostatic potential: blue (positive charge), red (negative charge). From PDB entries 4W7J and 2BOQ, respectively. 
On the other hand, the initial rates of DyP and VP oxidation of para-nitrophenol in the presence of inorganic nitrite revealed a progressive inactivation as nitrite concentration increases, in agreement with previous studies [4]. DyP was more affected by nitrite with only $16 \%$ of initial activity in the presence of $1 \mu \mathrm{M} \mathrm{NaNO}$ 2 while VP maintained $38 \%$ activity under the same conditions (Fig. S8).

More importantly, the catalytic efficiency of the W377S and W164S variants is reduced to less than $5 \%$ of those of the respective native enzymes. No significant changes of the catalytic constants are observed for the surface-Tyr variant (Y337S) and the occluded-channel variant (G169L) (Fig. 3 and Table 1). In summary, although some remaining activity is detected in the DyP and VP tryptophan-less variants, the results strongly supports that these tryptophan residues are playing a major role in the oxidation of nitrophenols by DyP and VP.

\subsection{Comparison of DyP and VP reduction potentials}

To investigate if the above $k_{\text {cat }}$ differences were due to differences in the oxidation power of DyP and VP, the standard reduction potentials $\left(\mathrm{E}^{\circ}\right)$ of both enzymes were estimated here. Most of the information available concerns the $\mathrm{Fe}^{3+} / \mathrm{Fe}^{2+}$ pair [19], which is not part of the catalytic cycle of ligninolytic and other fungal peroxidases. However, the reduction potentials of the reactive CI and CII states of LiP (and its evolutionary ancestors) have been recently measured [14] with the stopped-flow method also used to measure the reduction potentials of some animal peroxidases and fungal heme-thiolate peroxidases [20,21]. This method, which is based on rapid spectrophometry estimation (Fig. S4) of the equilibrium concentrations of both enzyme and substrate, provided a slightly lower $\mathrm{E}^{\circ \prime}(\mathrm{CI} / \mathrm{RS})$ value for $A$. auricula-judae DyP $(1.368 \pm 0.004$ V) than for P. eryngii VP $(1.383 \pm 0.004 \mathrm{~V})$ (Tables S1 and S2), being in both cases higher than the redox potentials of nitrophenols (e.g. para-nitrophenol $1.23 \mathrm{~V} \mathrm{[3].} \mathrm{Therefore,} \mathrm{other} \mathrm{factors,}$ such as better substrate positioning facilitating electron transfer, should be responsible for the higher activity of the latter enzyme on the different nitrophenols (Table 1).

\subsection{Substrate docking on crystal structures and in silico variants}

Trying to further rationalize the above differences in kinetic constants, the three nitrophenol isomers were docked on the DyP and VP crystal structures using the AutoDock software. The 100 poses of ortho, meta and para isomers calculated in independent docking runs for DyP and VP are shown in Fig. S9. Those poses with the best (lowest) binding energy are shown in Fig. S10.

The higher VP affinity for nitrophenols (as shown by lower $K_{\mathrm{m}}$ values) could be related to a stronger enzyme-substrate interaction mediated by several $\mathrm{H}$-bonds involving the guanidinium group of Arg257 and the amino group of Lys253. By contrast, the existence of only hydrophobic contacts with residues of the catalytic tryptophan environment, and/or single H-bonding interactions with the amide side chain of Asn328 or Asn380, would be responsible for the lower DyP affinity. Concerning activity, the different $k_{\text {cat }}$ values observed are no easily explained by the docking results. The substrate positioning - a combination of distance to catalytic tryptophan (always remaining in the 3.3-3.8 $\AA$ range for the best poses) and orientation - limits the electron transfer and the turnover and establish the differences observed.

\subsection{Concluding remarks}


DyP-type peroxidases are unrelated at the sequence level to classical ligninolytic peroxidases (VP, LiP or MnP). They also lack the typical heme-pocket residues of plant and fungal peroxidases, which comprise proximal histidine and distal histidine and arginine [17]. Moreover, in base to their tertiary structure, DyPs and classical ligninolytic peroxidases belong to unrelated superfamilies: the DyP-chlorite dismutase superfamily and the peroxidase-catalase superfamily, respectively [22]. However, as VPs and LiPs [9,23], DyPs are able to oxidize phenolic and nonphenolic aromatic compounds through a LRET pathway that involves a surface exposed catalytic tryptophan [8]. Such easily accessible oxidation site is consistent with the proposed nitration mechanism by peroxidases involving reactive nitrophenoxy and nitro free radicals or nitryl ion [5]. These are short-lived nitrating agents, whose interaction with the target substrates (nitrophenols) would be much easier if generated at the protein surface than in the buried heme pocket. In the present study, we demonstrate how these two unrelated enzyme types oxidize nitrophenols at a surface tryptophan residue, pointing to a functional convergent evolution for oxidation of aromatics, even in absence of a specific selection pressure for nitrophenols, given that nitrated phenols appear in nature recently as a result of industrial activity.

\section{Funding}

This work was supported by the INDOX European project (KBBE-2013-7-613549) and the BIO2017-86559-R project of the Spanish Ministry of Economy, Industry and Competitiveness, co-financed by FEDER funds.

\section{Competing interests}

The authors declare that they have no competing interests.

\section{Acknowledgements}

The Protein Chemistry service at CIB is acknowledged for the LC-PDA/MS analyses of reaction products.

\section{Appendix A. Supplementary data}

It includes two Tables providing parameters of the redox equilibria of DyP and VP for reduction potential calculation (Tables S1 and S2, respectively); and seven Figures showing spectra of resting state VP, DyP and its mutated variants (Fig. S1), calibration curves of nitro- and dinitrophenols (Fig. S2), spectra of nitrophenol oxidation for extinction coefficient calculation (Fig. S3), spectral changes in CI formation (Fig. S4), LC-PDA/MS analyses of ortho-, meta and paranitrophenol reactions (Figs. S5-S7, respectively), para-nitrophenol oxidation in presence of nitrite (Fig. S8), and docking of nitrophenols on DyP and VP (Fig. S9 and S10).

\section{References}

[1] A. Boehncke, G. Koennecker, I. Mangelsdorf, A. Wibbertmann, Mononitrophenols, World Health Organization, Geneva, 2019. 
[2] H. Teramoto, H. Tanaka, H. Wariishi, Appl. Microbiol. Biotechnol. 66 (2004) 312-317.

[3] C. Liers, E. Aranda, E. Strittmatter, K. Piontek, D.A. Plattner, H. Zorn, R. Ullrich, M. Hofrichter, J. Mol. Catal. B-Enzym. 103 (2014) 41-46.

[4] E. Büttner, R. Ullrich, E. Strittmatter, K. Piontek, D.A. Plattner, M. Hofrichter, C. Liers, Arch. Biochem. Biophys. 574 (2015) 86-92.

[5] I.J. Massey, M.D. Aitken, L.M. Ball, P.E. Heck, Environmental Toxicology and Chemistry. 13 (1994) 1743-1752.

[6] T. Yoshida, H. Tsuge, T. Hisabori, Y. Sugano, FEBS Lett. 586 (2012) 4351-4356.

[7] E. Strittmatter, C. Liers, R. Ullrich, S. Wachter, M. Hofrichter, D.A. Plattner, K. Piontek, J. Biol. Chem. 288 (2013) 4095-4102.

[8] D. Linde, R. Pogni, M. Cañellas, F. Lucas, V. Guallar, M.C. Baratto, A. Sinicropi, V. SáezJiménez, C. Coscolín, A. Romero, F.J. Medrano, F.J. Ruiz-Dueñas, A.T. Martínez, Biochem. J. 466 (2015) 253-262.

[9] M. Pérez-Boada, F.J. Ruiz-Dueñas, R. Pogni, R. Basosi, T. Choinowski, M.J. Martínez, K. Piontek, A.T. Martínez, J. Mol. Biol. 354 (2005) 385-402.

[10] M. Morales, M.J. Mate, A. Romero, M.J. Martínez, A.T. Martínez, F.J. Ruiz-Dueñas, J. Biol. Chem. 287 (2012) 41053-41067.

[11] V. Sáez-Jiménez, J. Rencoret, M.A. Rodríguez-Carvajal, A. Gutiérrez, F.J. Ruiz-Dueñas, A.T. Martínez, Biotechnol. Biofuels. 9:198 (2016).

[12] D. Linde, C. Coscolín, C. Liers, M. Hofrichter, A.T. Martínez, F.J. Ruiz-Dueñas, Protein Express. Purif. 103 (2014) 28-37.

[13] M. Pérez-Boada, W.A. Doyle, F.J. Ruiz-Dueñas, M.J. Martínez, A.T. Martínez, A.T. Smith, Enzyme Microb. Technol. 30 (2002) 518-524.

[14] I. Ayuso-Fernández, A.L. De Lacey, F.J. Cañada, F.J. Ruiz-Dueñas, A.T. Martínez, Chem. -Eur. J. 25 (2018) 2708-2712.

[15] W.H. Koppenol, Bioelectrochem. Bioenerg. 18 (1987) 3-11.

[16] G.M. Morris, R. Huey, W. Lindstrom, M.F. Sanner, R.K. Belew, D.S. Goodsell, A.J. Olson, J. Comp. Chem. 30 (2009) 2785-2791.

[17] D. Linde, F.J. Ruiz-Dueñas, E. Fernández-Fueyo, V. Guallar, K.E. Hammel, R. Pogni, A.T. Martínez, Arch. Biochem. Biophys. 574 (2015) 66-74.

[18] F.J. Ruiz-Dueñas, M. Morales, M.J. Mate, A. Romero, M.J. Martínez, A.T. Smith, A.T. Martínez, Biochemistry. 47 (2008) 1685-1695.

[19] C.D. Millis, D. Cai, M.T. Stankovich, M. Tien, Biochemistry. 28 (1989) 8484-8489.

[20] G. Battistuzzi, M. Bellei, C.A. Bortolotti, M. Sola, Arch. Biochem. Biophys. 500 (2010) 21-36.

[21] X.S. Wang, S. Peter, R. Ullrich, M. Hofrichter, J.T. Groves, Angew. Chem. Int. Ed. 52 (2013) 9238-9241.

[22] M. Zámocký, S. Hofbauer, I. Schaffner, B. Gasselhuber, A. Nicolussi, M. Soudi, K.F. Pirker, P.G. Furtmüller, C. Obinger, Arch. Biochem. Biophys. 574 (2015) 108-119.

[23] W.A. Doyle, W. Blodig, N.C. Veitch, K. Piontek, A.T. Smith, Biochemistry. 37 (1998) 15097-15105. 


\title{
Supplementary Data
}

\section{Different fungal peroxidases oxidize nitrophenols at a surface catalytic tryptophan}

\author{
Dolores Linde, Iván Ayuso-Fernández, Francisco J. Ruiz-Dueñas, Angel T. Martínez* \\ Centro de Investigaciones Biológicas, CSIC, Ramiro de Maeztu 9, E-28040 Madrid, Spain \\ *E-mail: $\underline{\text { ATMartinez@cib.csic.es }}$
}

Supplementary data include two Tables providing parameters of the redox equilibria of DyP and VP for reduction potential calculation (Tables S1 and S2, respectively); and seven Figures showing spectra of resting state VP, DyP and its mutated variants (Fig. S1), calibration curves of nitro- and dinitro-phenols (Fig. S2), spectra of nitrophenol oxidation for extinction coefficient calculation (Fig. S3), spectral changes in CI formation (Fig. S4), LC-PDA/MS analyses of ortho, meta- and para-nitrophenol reactions (Figs. S5-S7, respectively), para-nitrophenol oxidation in presence of nitrite (Fig. S8), and docking of nitrophenols on DyP and VP (Figs. S9 and S10).

Table S1. Parameters of the redox equilibrium and calculated $\mathrm{E}^{\mathrm{ol}}$ of the CI/RS redox couple of A. auricula-judae DyP, as a function of the initial concentration of $\mathrm{H}_{2} \mathrm{O}_{2}$ (all reactions at optimal $\mathrm{pH} 3$ ).

\begin{tabular}{ccccc}
\hline Initial $\mathrm{H}_{2} \mathrm{O}_{2}$ & \multicolumn{3}{c}{ Equilibrium concentrations $(\mu \mathrm{M})$} & \multirow{2}{*}{$\mathrm{E}^{\text {o' }}(\mathrm{V})$} \\
\cline { 2 - 4 }$(\mu \mathrm{M})$ & $\mathrm{DyP}$ CI & DyP RS & $\mathrm{H}_{2} \mathrm{O}_{2}$ & \\
\hline 2 & 1.699 & 2.701 & 0.301 & 1.368 \\
4 & 2.963 & 1.437 & 1.037 & 1.373 \\
6 & 3.948 & 0.452 & 2.052 & 1.363 \\
8 & 4.129 & 0.271 & 3.871 & 1.365 \\
Mean and 95\% confidence interval: & & & $1.368 \pm 0.004$ \\
\hline
\end{tabular}

Table S2. Parameters of the redox equilibrium and calculated $\mathrm{E}^{\mathrm{ol}}$ of the $\mathrm{CI} / \mathrm{RS}$ redox couple of $P$. eryngii VP, as a function of the initial concentration of $\mathrm{H}_{2} \mathrm{O}_{2}$ (all reactions at optimal $\mathrm{pH} 3$ ).

\begin{tabular}{|c|c|c|c|c|}
\hline \multirow{2}{*}{$\begin{array}{l}\text { Initial } \mathrm{H}_{2} \mathrm{O}_{2} \\
\quad(\mu \mathrm{M})\end{array}$} & \multicolumn{3}{|c|}{ Equilibrium concentrations $(\mu \mathrm{M})$} & \multirow[t]{2}{*}{$\mathrm{E}^{\mathrm{o}}(\mathrm{V})$} \\
\hline & VP CI & VP RS & $\mathrm{H}_{2} \mathrm{O}_{2}$ & \\
\hline 0.50 & 0.34 & 1.76 & 0.16 & 1.381 \\
\hline 1.00 & 0.56 & 1.54 & 0.44 & 1.385 \\
\hline 2.00 & 0.90 & 1.20 & 1.10 & 1.388 \\
\hline 3.00 & 1.39 & 0.71 & 1.61 & 1.380 \\
\hline \multicolumn{4}{|c|}{ Mean and $95 \%$ confidence interval: } & $1.383 \pm 0.004$ \\
\hline
\end{tabular}



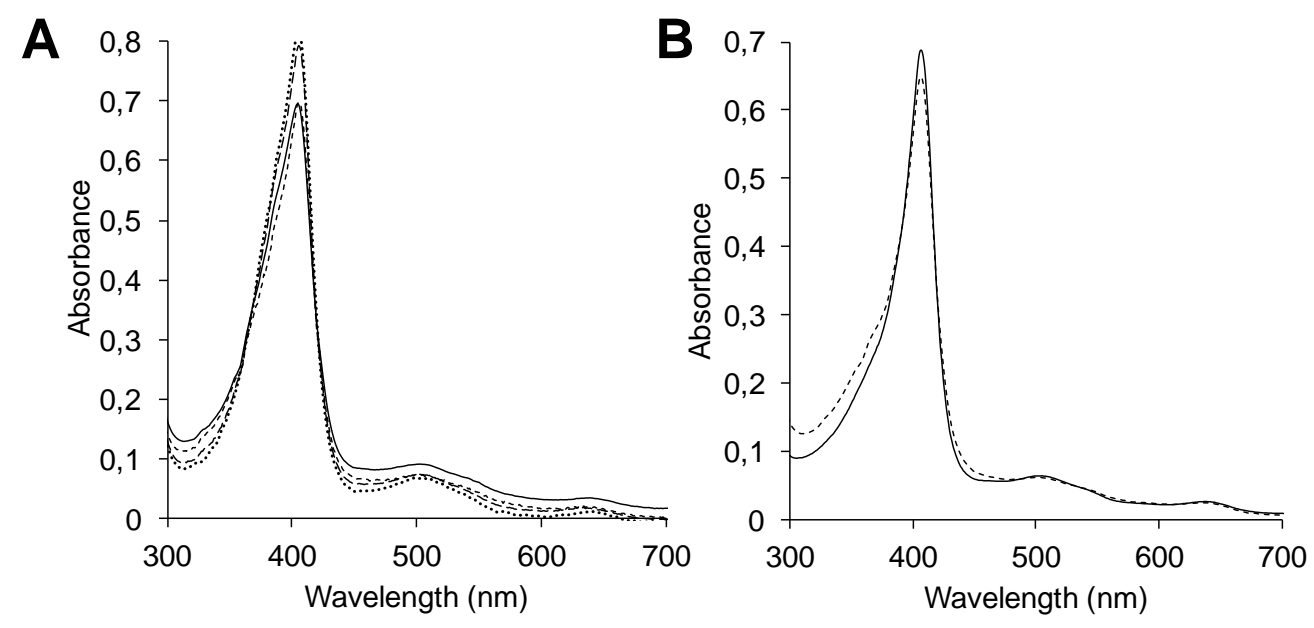

Fig. S1. Absorption spectra of $\sim 6 \mu \mathrm{M}$ native DyP and its W377S, Y337S and G169L mutated variants (A) and native VP and its $\mathrm{W} 164 \mathrm{~S}$ mutated variant (B) in $10 \mathrm{mM}$ acetate, $\mathrm{pH}$ 5. Native enzymes are indicated in continuous line, tryptophan less variants (W164S and W377S) in short dashed lines, Y337S in dotted line and G169L in long dashed line. 

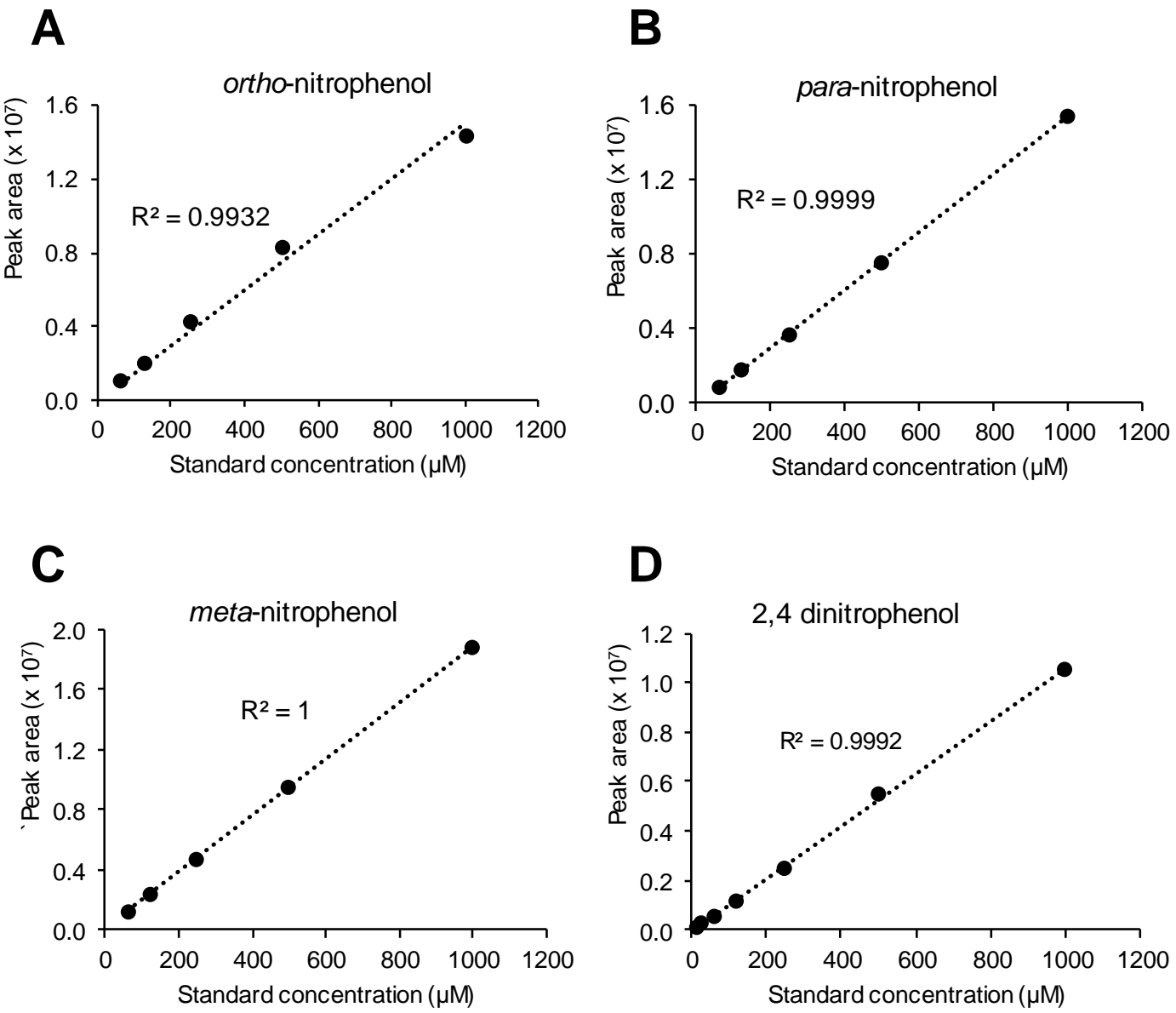

Fig. S2. Calibration curves for quantitation of ortho- (A), meta- (B) and para-nitrophenol (C) and 2,4dinitrophenol (D) by LC-PDA/MS (total scan of 200-500 nm) using authentic standards. 

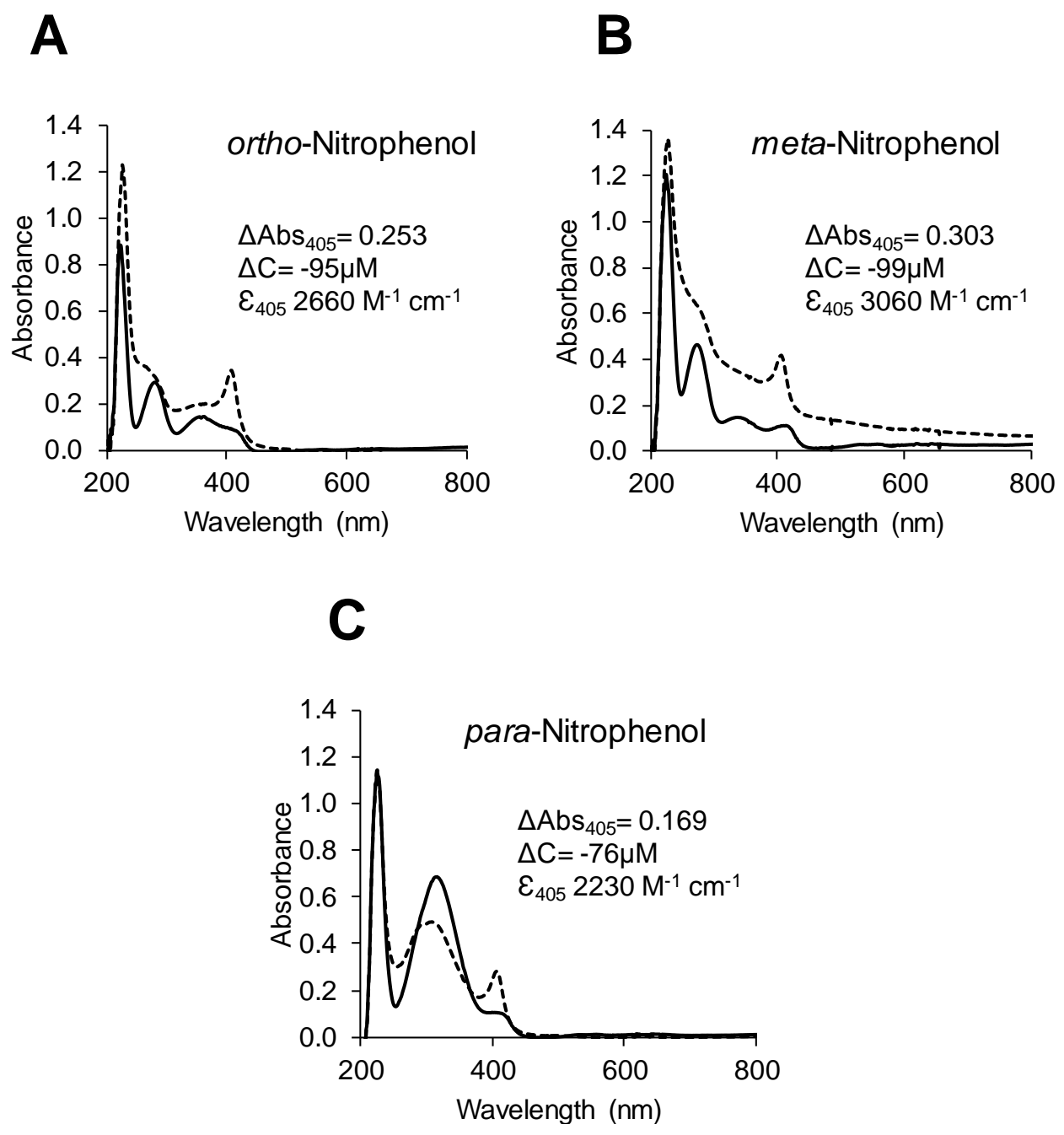

Fig. S3. Spectra of ortho- (A), meta- (B) and para-nitrophenol (C) oxidation for extinction coefficient calculation. The reactions included $0.1 \mathrm{mM}$ substrate, $3.5 \mu \mathrm{M}$ DyP, and $1 \mathrm{mM}$ peroxide in $0.1 \mathrm{M}$ acetate, $\mathrm{pH}$ 4.3. Continuous line corresponds to spectra at time 0 and dashed line after 25 min (ortho- and para-) and 90 min (meta-) reaction. The increase of $405-\mathrm{nm}$ absorbance $\left(\Delta \mathrm{Abs}_{405}\right)$ is shown together with the decrease of substrate concentration $(\Delta \mathrm{C})$ from LC-PDA/MS, and the resulting extinction coefficient $\left(\varepsilon_{405}\right)$ values. 

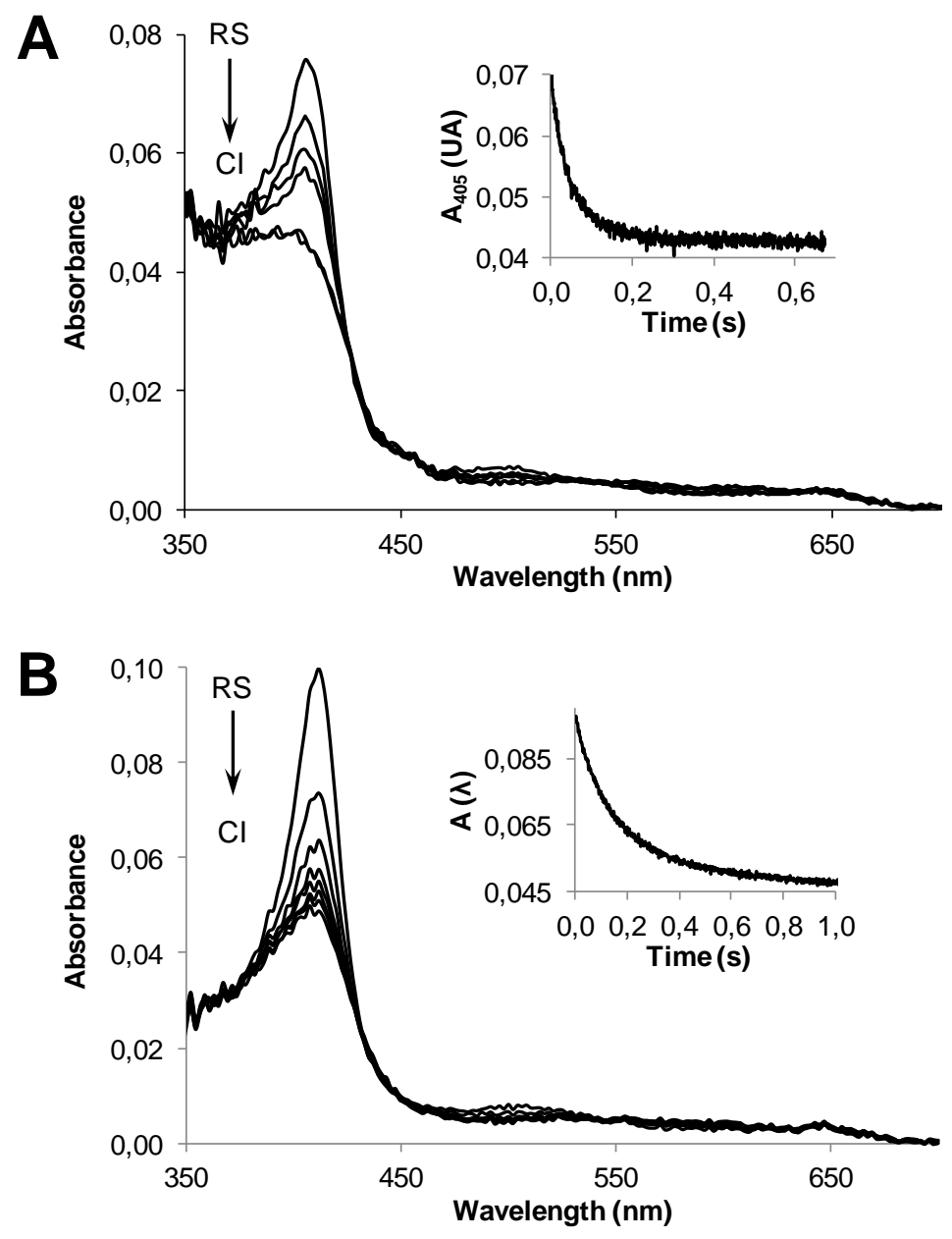

Fig. S4. Spectral changes upon mixing $4 \mu \mathrm{M}$ VP (A) and DyP (B) with $6 \mu \mathrm{M} \mathrm{H}_{2} \mathrm{O}_{2}$ to follow CI formation. The insets show time traces near Soret maximum (at $410 \mathrm{~nm}$ for VP and $405 \mathrm{~nm}$ for DyP) to attain equilibrium conditions. All reactions were at optimal $\mathrm{pH} 3$, and $25^{\circ} \mathrm{C}$. 


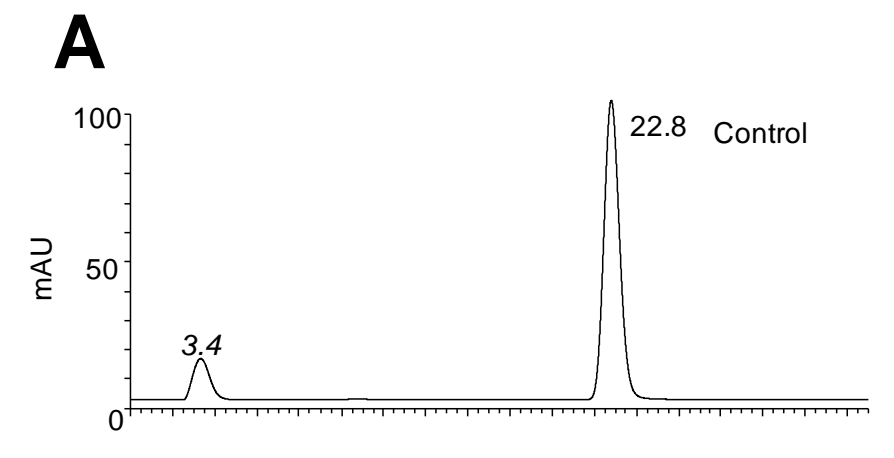

B
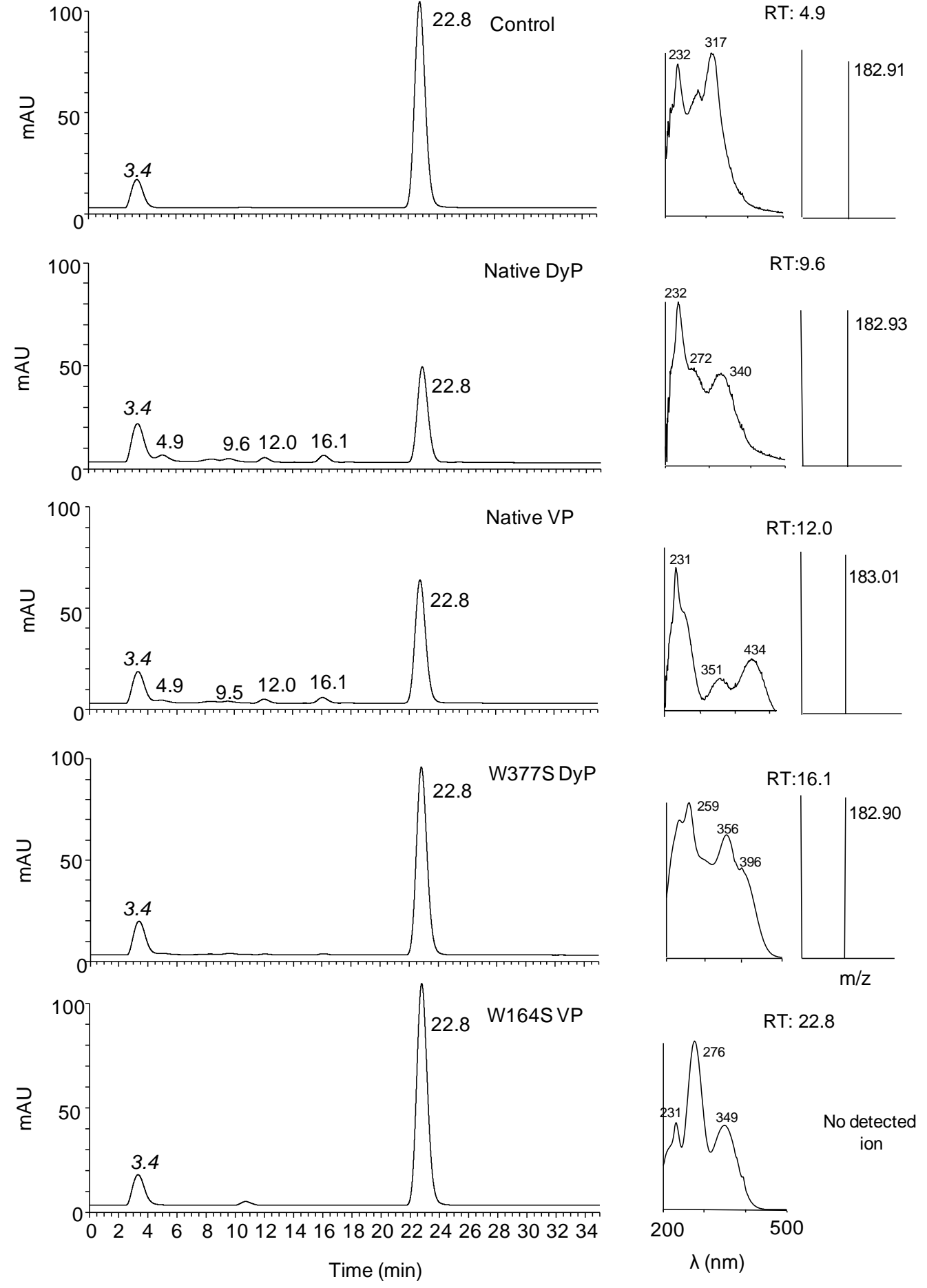

Fig. S5. LC-PDA/MS analysis of ortho-nitrophenol reactions (30 min). A) Chromatograms (200-500 nm total scan) of reactions with DyP, VP and their W377S and W164S variants, and control without enzyme. B) Absorption spectra (left) and molecular ions (right) of the detected peaks, corresponding to substrate (22.8 $\mathrm{min}), 2$,4-dinitrophenol (16.1 $\mathrm{min}), 2,6$-dinitrophenol $(12.0 \mathrm{~min})$, and three unidentified products. Artifactual peak with RT 3.4 is due to sample injection. 

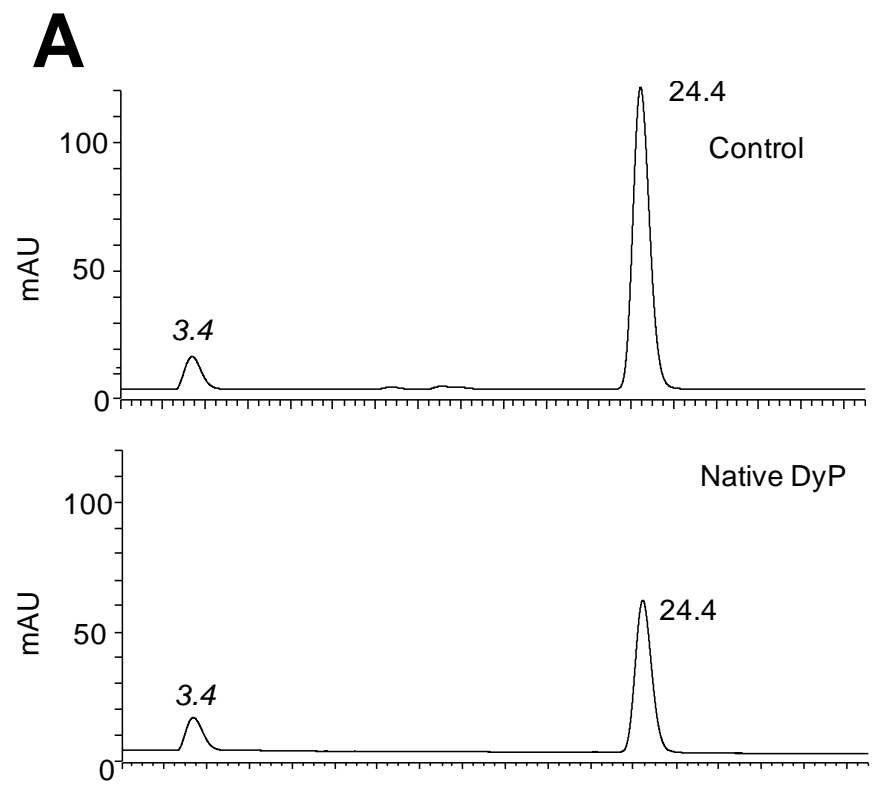

B
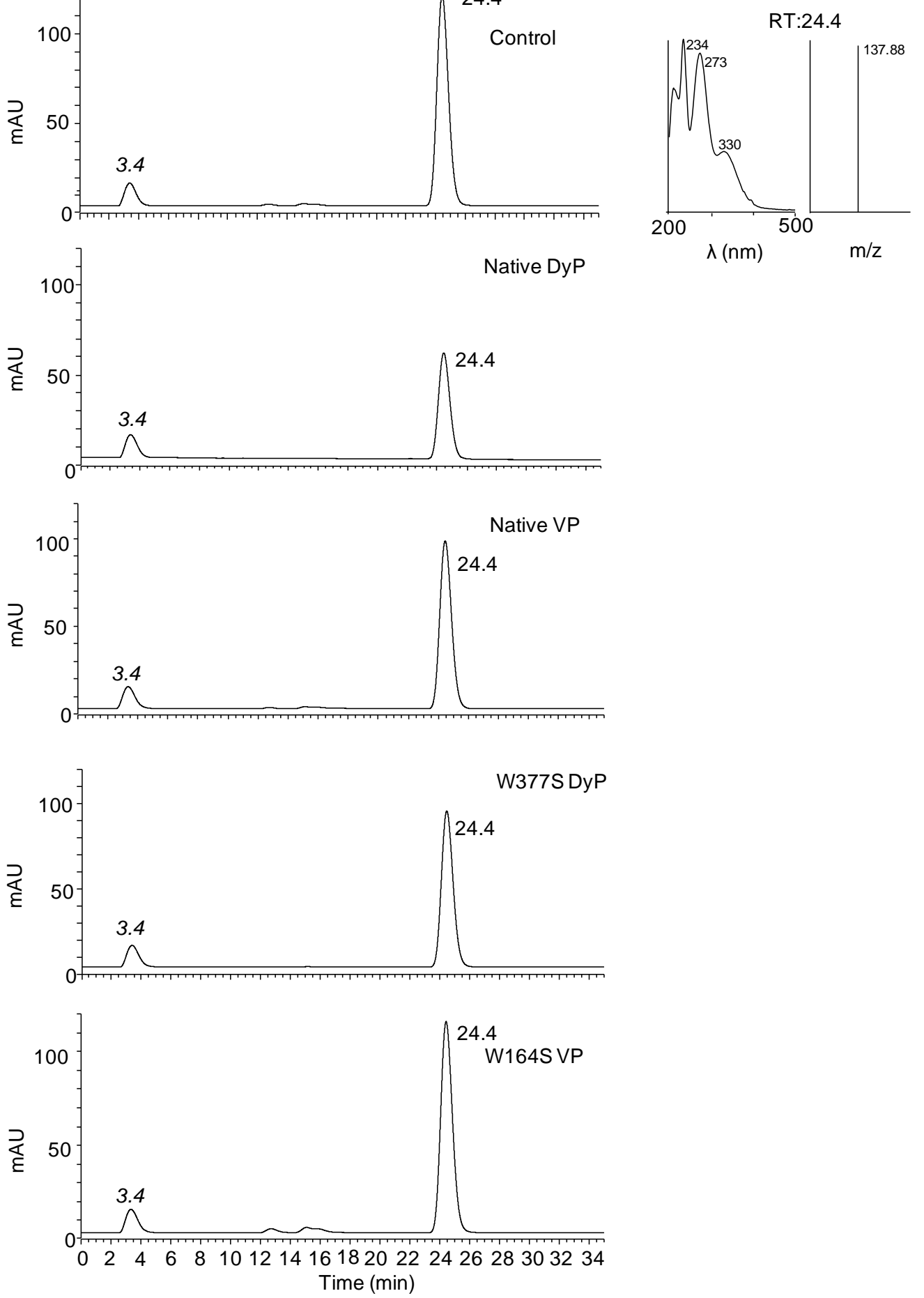

Fig. S6. LC-PDA/MS analysis of meta-nitrophenol reactions (30 min). A) Chromatograms (200-500 $\mathrm{nm}$ total scan) of reactions with DyP, VP and their W377S and W164S variants, and control without enzyme. B) Absorption spectrum (left) and molecular ion (right) of the only detected peak, corresponding to substrate (24.4 min). Artifactual peak with RT 3.4 is due to sample injection. 


\section{A}
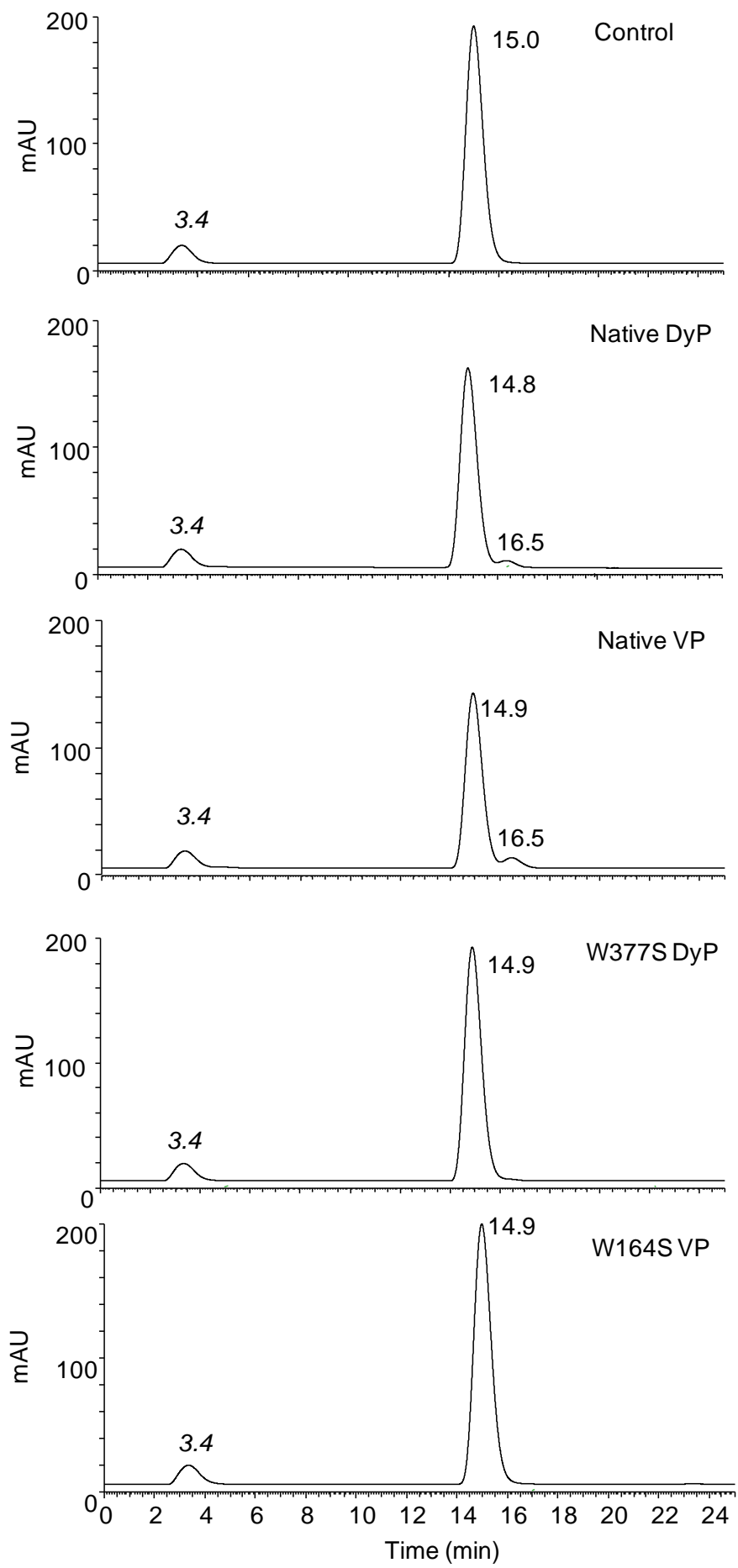

B

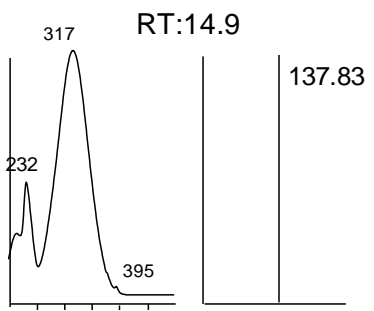

$\mathrm{RT}: 16.5$

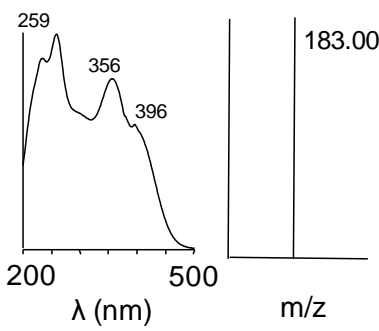

Fig. S7. LC-PDA/MS analysis of para-nitrophenol reactions (30 min). A) Chromatograms (200-500 $\mathrm{nm}$ total scan) of reactions with DyP, VP and their W377S and W164S variants, and control without enzyme. B) Absorption spectra (left) and molecular ions (right) of the detected peaks, corresponding to substrate (14.9 min) and 2,4-dinitrophenol (16.5 min). Artifactual peak with RT 3.4 is due to sample injection. 


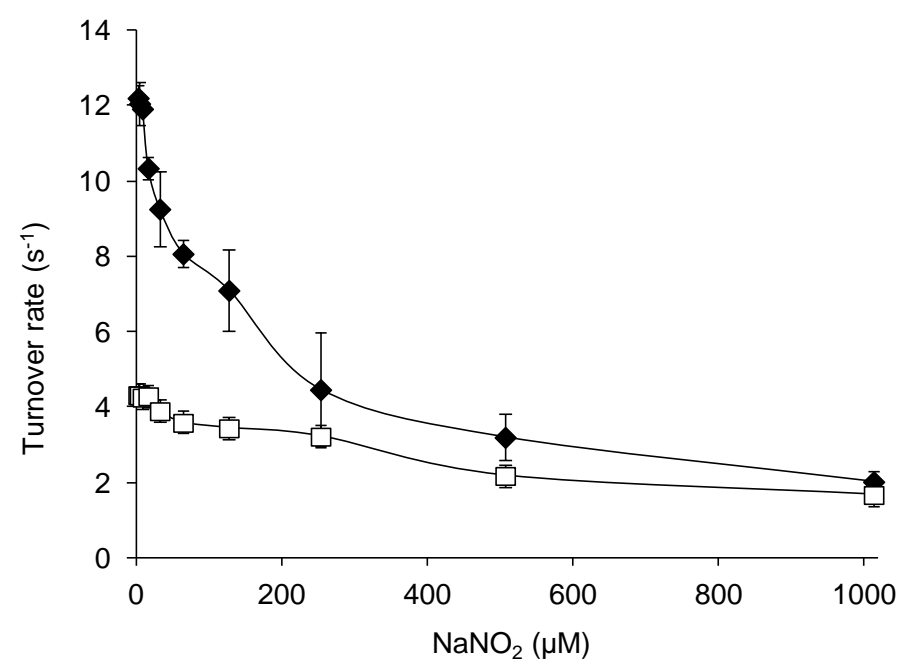

Fig. S8. Oxidation of para-nitrophenol by A. auricula-judae DyP (diamonds) and P. eryngii VP (squares) in the presence of increasing concentrations of $\mathrm{NaNO}_{2}$. Reactions were performed in 0.1

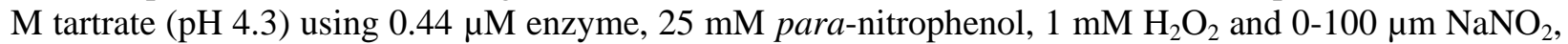
and followed spectrophotometrically at $405 \mathrm{~nm}$. Means and standard errors are shown.
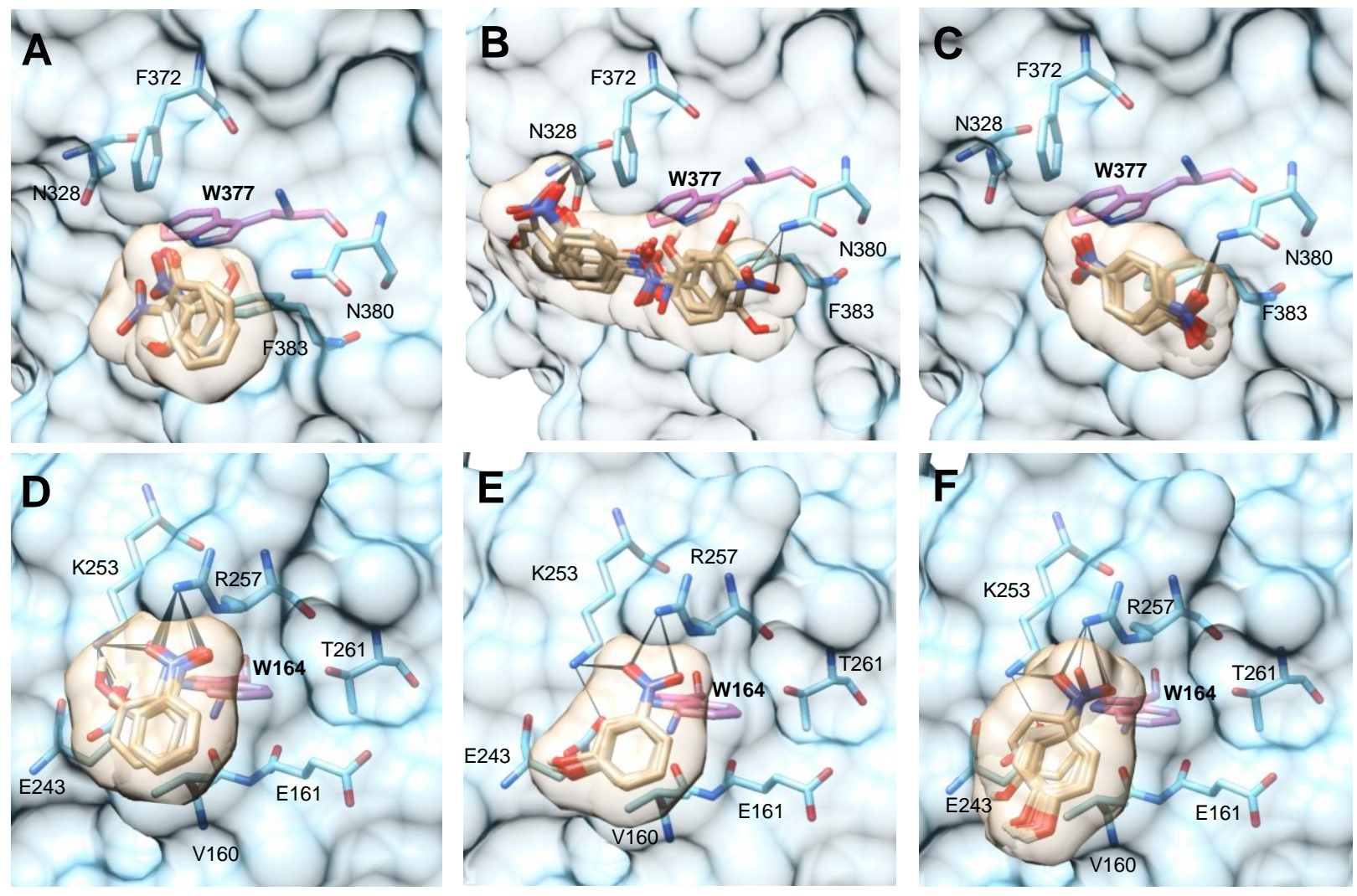

Fig. S9. Results from 100 docking runs of ortho- $(\mathbf{A}, \mathbf{D})$, meta- $(\mathbf{B}, \mathbf{E})$ and para-nitrophenol $(\mathbf{C}, \mathbf{F})$ (with most substrate molecules overlapping) on recombinant $A$. auricula-judae DyP (A-C) and $P$. eryngii VP (D-F) crystal structures (PDB 4W7J and 2BOQ, respectively). H-bonds are indicated with black lines. 

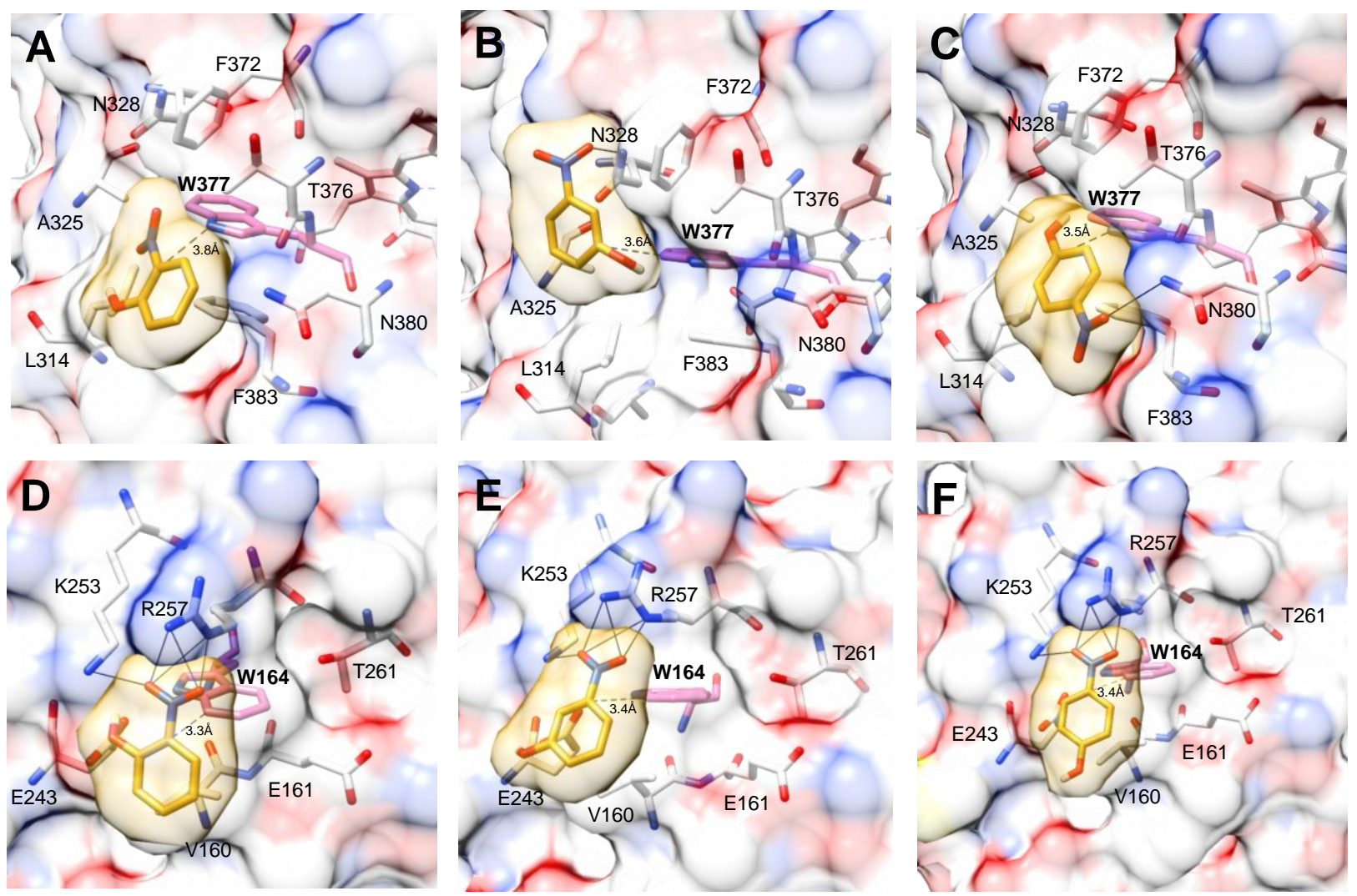

Fig. S10. Poses with the best (lowest) binding energy after docking of ortho- $(\mathbf{A}, \mathbf{D})$, meta- $(\mathbf{B}, \mathbf{E})$ and para-nitrophenol $(\mathbf{C , F})$ on A. auricula-judae DyP (A-C) and P. eryngii VP (D-F) crystal structures (PDB 4W7J and 2BOQ, respectively), among the 100 poses per simulation in Fig. S9 . H-bonds are indicated with black lines, and ring-ring distances with dashed lines. 